\title{
Evaluation of factors affecting the frequency and clinical course of COVID-19 in patients using anti-TNF-alpha agents
}

\author{
Seyma Baslılar* (1), Ozlem Pehlivan²
}

\begin{abstract}
SUMMARY
OBJECTIVES: Patients being treated with anti-tumor necrosis factor-alpha (anti-TNF-alpha) agents were reported to have better prognosis related to COVID-19. We evaluated the factors affecting the frequency, clinical course, and outcome of COVID-19 in patients treated with anti-TNF-alpha agents. METHODS: Patients with rheumatoid diseases and chronic inflammatory bowel diseases treated with anti-TNF-alpha agents were evaluated retrospectively. The laboratory data in routine visits, frequency of COVID-19, pneumonia, hospitalization and/or intensive care unit (ICU) follow-up and, mortality were recorded. The factors related to COVID-19 frequency and clinical outcome were evaluated. RESULTS: A total of 324 patients (177 males [54.6\%] and 147 females [45.4\%], mean age: $45.3 \pm 12.16$ years) was included in the study. In all, 44 (13.6\%) patients had COVID-19; of these, 11 (25\%) developed pneumonia, 7 (15.9\%) were hospitalized, and 1 (2.3\%) was followed up in ICU. There was no mortality. The patients with COVID-19 pneumonia were older (mean age: $52 \pm 11$ years versus $41 \pm 12$ years, $p=0.01$ ), had hypertension and coronary artery disease more frequently ( 5 cases [55.6\%] versus 4 cases [ 44.4 ], $p=0.02$ and 2 cases [100\%] versus 0 cases [0\%], $p=0.014$, respectively), and lower eosinophil $\%(1.35 \pm 1.79 \%$ versus $2.3 \pm 1.45 \%, p=0.016)$. The diabetes mellitus was more frequent ( 66.7 versus $33.3 \%, p=0.013)$, and mean eosinophil \% was lower among inpatients compared with outpatients $(1.29 \pm 2.22 \%$ versus $2.19 \pm 1.37 \%, p=0.02)$.
\end{abstract}

CONCLUSIONS: We concluded that the patients treated with anti-TNF-alpha agents having COVID-19 might have mild clinical course and better prognosis.

KEYWORDS: Tumor necrosis factor-alpha. COVID-19. Pneumonia. Mortality. Eosinophils.

\section{INTRODUCTION}

It has been reported that patients being treated with anti-tumor necrosis factor alpha (anti-TNF-alpha) agents for rheumatoid diseases (RDs) had a lower risk of hospitalization related to coronavirus disease 2019 (COVID-19) and a better prognosis compared with those treated with other anti-rheumatoid agents especially corticosteroids $(\mathrm{CS})^{1-5}$. But the factors affecting the clinical course and outcome in these specific groups of patients were not examined in detail. In this retrospective observational study, we evaluated patients treated with antiTNF-alpha agents for RD and chronic inflammatory bowel disease (CIBD) to assess the frequency of COVID-19 and the factors affecting the clinical course and outcome.

\section{METHODS}

Adult patients with RD (rheumatoid arthritis [RA], ankylosing spondylitis [AS], psoriatic arthritis [PsA]) and CIBD (Crohn's disease and ulcerative colitis [UC]) who were treated with antiTNF-alpha agents at least for 12 months and applied for the Umraniye Training and Research Hospital Pulmonology and Rheumatology Department between March 15, 2020 and

\footnotetext{
1 Umraniye Training and Research Hospital, Department of Pulmonology - Istanbul, Turkey.

¿Umraniye Training and Research Hospital, Department of Rheumatology - Istanbul, Turkey.

*Corresponding author: seymabaslilar@yahoo.com

Conflicts of interest: the authors declare there are no conflicts of interest. Funding: none.

Received on July 27, 2021. Accepted on August 01, 2021.
} 
March 01, 2021 were evaluated retrospectively. The study was approved by the local ethics committee (Approval number B.1 0.1.TKH.4.34.H.G.p.0.01/111). The healthcare workers and patients over 65 years of age were excluded because they were included in the national vaccination schedule for severe acute respiratory syndrome coronavirus 2 (SARS-CoV-2). The data about demographic information, medical history, body mass index (BMI), smoking status, comorbidities such as hypertension (HT), diabetes mellitus (DM), asthma, chronic obstructive pulmonary disease (COPD), and coronary artery disease (CAD); the diagnosis of $\mathrm{RD}$, anti-TNF-alpha agent, and additional pharmacological therapies used for RD and CIBD; and the duration of the anti-TNF-alpha therapy, tuberculosis skin test (TST) result, and laboratory parameters (i.e., leukocyte, neutrophil, lymphocyte and eosinophil count, and serum level of C-reactive protein) performed in the routine follow-up visit (in patients with a history of COVID-19, the laboratory tests in the last visit before the SARS-CoV-2 infection), and the history of COVID-19 was extracted from the medical files. The presence and radiological severity of pneumonia and the data for clinical course and outcome (need and duration of hospitalization and/ or intensive care unit (ICU) follow-up, oxygen, CS, anti-cytokine treatment, intubation, and mortality) were also recorded in patients with COVID-19. In patients with pneumonia, the severity was degreed on thorax computerized tomography (CT) according to the scoring system offered by Bernheim A, et $\mathrm{al}^{\mathrm{l}, 7}$.

The patients were divided into two groups, namely, COVID$19(+)$ and COVID-19 (-) and compared in terms of age, sex, BMI, smoking status, comorbidities, the diagnosis of $\mathrm{RD} /$ CIBD, anti-TNF-alpha agent used, additional pharmacological therapies given for $\mathrm{RD} / \mathrm{CIBD}$, the duration of the anti-TNFalpha therapy, TST result, and laboratory parameters. In the COVID-19 (+) group, the relationship of these factors with the presence and radiological severity of pneumonia, hospitalization, and ICU follow-up and clinical outcome was analyzed further.

\section{Statistical analysis}

Patient data were collected were analyzed with the IBM Statistical Package for the Social Sciences (SPSS) for Windows 23.0 package program (Statistical Package for the Social Sciences, Chicago, IL, USA). The discrete data were given as frequency and percentage. The mean \pm standard deviation for continuous data was given as descriptive value. The Mann-Whitney U test was used to compare the two groups. The Pearson's chisquare test and the Fisher-Freeman-Halton test were used to evaluate the relationship between the categorical features and the frequency and parameters related to the clinical course of COVID-19. The results were considered statistically significant when the $\mathrm{p}<0.05$.

\section{RESULTS}

A total of 324 patients (177 males [54.6\%] and 147 females [ $45.4 \%$ ] with a mean age of $45.3 \pm 12.16$ years) were included in this study. There were 280 patients (86.4\%) in COVID-19 (-) and 44 patients (13.6\%) in COVID-19 (+) group. Comparison of the data between the two groups is shown in Table 1 . The mean age of the patients was $46 \pm 12$ years in the COVID-19 (-) and $44 \pm 13$ years in the COVID-19 $(+)$ group $(\mathrm{p}=0.364)$. The both sexes were evenly distributed in COVID-19 (-) and COVID-19 (+) groups (154 males [55\%] versus 126 females [45\%], and 23 males [52.3\%] versus 21 females [ $47.7 \%$ ], respectively, $\mathrm{p}=0.751$ ). AS was the most frequent disease followed by RA, Crohn's disease, PsA, and UC in COVID-19 (-) and (+) groups (129 cases versus 20 cases, 65 cases versus 14 cases, 45 cases versus 7 cases, 37 cases versus 2 cases, and 3 cases versus 1 case, respectively, $\mathrm{p}=0.411$ ).

The information for BMI was available in 47 patients, and the mean BMI was similar in the COVID-19 (-) and (+) groups (27.6 \pm 4.2 and $27.24 \pm 2.64$, respectively, $\mathrm{p}=0.886$ ). There was no significant difference between the two groups in terms of smoking amount, comorbidities, anti-TNF-alpha agent, mean duration of anti-TNF-alpha treatment, and TST result $(\mathrm{p}>0.05)$.

Among the COVID-19 (+) group, 11 patients (25\%) developed pneumonia. The information about pneumonia was lacking in 1 patient. Of note, 4 cases (36.3\%) had mild, 5 cases (45.4\%) had moderate, and 2 cases (18.3\%) had severe pneumonia. Notably, 7 of the cases $(15.9 \%)$ were hospitalized, and 1 of them $(2.3 \%)$ was followed up in ICU; 2 cases (4.5\%) needed nasal oxygen, 1 case $(2.3 \%)$ needed high flow oxygen, 3 cases $(6.8 \%)$ needed CS treatment ( 2 of them needed pulse steroid), and 1 case (2.3\%) was treated with the anti-cytokine agent, i.e., tocilizumab. None of the cases was intubated or died. The relationship between the presence of pneumonia and the demographic, clinical, and laboratory data is shown in Table 2 . The distribution of sex among cases with and without pneumonia was similar ( 7 versus 15 males and 4 versus 17 females, respectively, $\mathrm{p}=0.337$ ). The patients with pneumonia were older significantly (mean age was $52 \pm 11$ years versus $41 \pm 12$ years, $\mathrm{p}=0.01$ ). In patients with pneumonia, HT and $\mathrm{CAD}$ were more frequent (5 cases [55.6\%] versus 4 cases [44.4], $\mathrm{p}=0.02 ; 2$ cases [100\%] versus 0 case [0\%], respectively, $\mathrm{p}=0.014)$, and the mean percentage of eosinophil was significantly lower $(1.35 \pm 1.79 \%$ vs. $2.3 \pm 1.45 \%, \mathrm{p}=0.016)$.

Notably, 7/44 (15.9\%) COVID-19 (+) cases were hospitalized. The comparison of demographic, clinical, and laboratory data in patients with and without a history of hospitalization is shown in Table 3. The frequency of $\mathrm{DM}$ was high, but that of $\mathrm{CAD}$ was low among inpatients compared with outpatients significantly $(66.7 \%$ versus $33.3 \%$ and $15.9 \%$ versus $37 \%, \mathrm{p}=0.013$ and $\mathrm{p}=0.001$, respectively). In hospitalized patients, the mean percentage of eosinophil was significantly lower $(1.29 \pm 2.22 \%$ versus $2.19 \pm 1.37 \%, \mathrm{p}=0.02)$. 
Table 1. Comparison of demographic, clinical, and laboratory data between COVID-19 (-) and (+) groups.

\begin{tabular}{|c|c|c|c|c|c|c|}
\hline & \multicolumn{2}{|c|}{ COVID-19 (-) } & \multicolumn{2}{|c|}{ COVID-19 (+) } & \multirow[b]{2}{*}{ p-value } \\
\hline & & $\mathrm{n}$ ormean & $\begin{array}{c}\% \text { or } \\
\text { Standard } \\
\text { deviation }\end{array}$ & $\mathrm{n}$ or mean & $\begin{array}{c}\% \text { or } \\
\text { standard } \\
\text { deviation }\end{array}$ & \\
\hline \multirow{2}{*}{ Sex } & Male & 154 & 86.9 & 23 & 13.1 & \multirow{2}{*}{0.751} \\
\hline & Female & 126 & 85.7 & 21 & 14.3 & \\
\hline \multirow{5}{*}{$\begin{array}{l}\text { Rheumatoid/chronic } \\
\text { inflammatory bowel disease }\end{array}$} & Crohn's disease & 45 & 86.5 & 7 & 13.5 & \multirow{5}{*}{0.411} \\
\hline & RA & 65 & 82.3 & 14 & 17.7 & \\
\hline & AS & 129 & 86.6 & 20 & 13.4 & \\
\hline & Ulcerative colitis & 3 & 75.0 & 1 & 25.0 & \\
\hline & Psoriatic arthritis & 37 & 94.9 & 2 & 5.1 & \\
\hline \multirow{6}{*}{ Anti-TNF-alpha agent } & Adalimumab & 101 & 84.9 & 18 & 15.1 & \multirow{6}{*}{0.928} \\
\hline & Etanercept & 57 & 87.7 & 8 & 12.3 & \\
\hline & Infliximab & 30 & 88.2 & 4 & 11.8 & \\
\hline & Golimumab & 52 & 89.7 & 6 & 10.3 & \\
\hline & Certolizumab & 35 & 81.4 & 8 & 18.6 & \\
\hline & Other & 4 & 100.0 & 0 & 0.0 & \\
\hline \multirow{5}{*}{ Comorbidities } & HT & 40 & 81.6 & 9 & 18.4 & 0.298 \\
\hline & DM & 31 & 91.2 & 3 & 8.8 & 0.383 \\
\hline & Asthma & 9 & 75.0 & 3 & 25.0 & 0.242 \\
\hline & COPD & 1 & 100 & 0 & 0 & - \\
\hline & CAD & 10 & 83.3 & 2 & 16.7 & 0.754 \\
\hline \multirow{2}{*}{ TST result } & Negative & 84 & 85.7 & 14 & 14.3 & \multirow{2}{*}{0.830} \\
\hline & Positive & 194 & 86.6 & 30 & 13.4 & \\
\hline \multicolumn{2}{|l|}{ Age (years) } & 46 & 12 & 44 & 13 & 0.364 \\
\hline \multicolumn{2}{|l|}{ BMI $\left(\mathrm{kg} / \mathrm{m}^{2}\right)$} & 27.6 & 4.2 & 27.24 & 2.64 & 0.886 \\
\hline \multicolumn{2}{|c|}{ Anti-TNF-alpha treatment duration (months) } & 61 & 29 & 61 & 30 & 0.708 \\
\hline \multicolumn{2}{|l|}{ Smoking (package/years) } & 4 & 9 & 1 & 2 & 0.235 \\
\hline \multicolumn{2}{|l|}{ CRP $(\mathrm{mg} / \mathrm{dL})$} & 0.94 & 1.25 & 1.47 & 2.75 & 0.304 \\
\hline \multicolumn{2}{|c|}{ Number of leukocytes $\left(\times 10^{3} / \mathrm{mL}\right)$} & 8378 & 4005 & 7855 & 1724 & 0.666 \\
\hline \multicolumn{2}{|c|}{ Number of neutrophils $\left(\times 10^{3} / \mathrm{mL}\right)$} & 4745 & 1911 & 4721 & 1392 & 0.637 \\
\hline \multicolumn{2}{|c|}{ Number of lymphocytes $\left(\times 10^{3} / \mathrm{mL}\right)$} & 2647 & 1048 & 2434 & 778 & 0.475 \\
\hline \multicolumn{2}{|l|}{ N/L ratio } & 2.06 & 1.33 & 2.22 & 1.3 & 0.120 \\
\hline \multicolumn{2}{|c|}{ Number of eosinophils $\left(\times 10^{3} / \mathrm{mL}\right)$} & 212 & 159 & 170 & 118 & 0.137 \\
\hline \multicolumn{2}{|l|}{ E/L ratio } & 0.085 & 0.077 & 0.106 & 0.202 & 0.805 \\
\hline \multicolumn{2}{|l|}{ Eosinophil (\%) } & 8.16 & 8.246 & 2.03 & 1.55 & 0.148 \\
\hline
\end{tabular}

BMI: body mass index; CRP: C-reactive protein; TNF: tumor necrosis factor; RA: rheumatoid arthritis; AS: ankylosing spondylitis; HT: hypertension; DM: diabetes mellitus; COPD: chronic obstructive pulmonary disease; CAD: coronary artery disease; TST: tuberculin skin test. 
Table 2. Comparison of demographic, clinical, and laboratory features in COVID-19 (+) patients without and with pneumonia.

\begin{tabular}{|c|c|c|c|c|c|c|}
\hline & \multicolumn{4}{|c|}{ Pneumonia } & \multirow{3}{*}{ p-value } \\
\hline & & \multicolumn{2}{|c|}{ No } & \multicolumn{2}{|c|}{ Yes } & \\
\hline & & $\mathrm{n}$ or mean & $\%$ or SD & $\mathrm{n}$ or mean & $\%$ or SD & \\
\hline \multirow{2}{*}{ Sex } & Male & 15 & 68.2 & 7 & 31.8 & \multirow{2}{*}{0.337} \\
\hline & Female & 17 & 81.0 & 4 & 19.0 & \\
\hline \multirow{5}{*}{$\begin{array}{l}\text { Rheumatoid/Chronic } \\
\text { inflammatory bowel disease }\end{array}$} & Crohn's disease & 4 & 66.7 & 2 & 33.3 & \multirow{5}{*}{0.543} \\
\hline & RA & 12 & 85.7 & 2 & 14.3 & \\
\hline & AS & 13 & 65.0 & 7 & 35.0 & \\
\hline & Ulcerative colitis & 1 & 100.0 & 0 & 0 & \\
\hline & Psoriatic arthritis & 2 & 100.0 & 0 & 0 & \\
\hline \multirow{6}{*}{ Anti-TNF-alpha agent } & Adalimumab & 13 & 76.5 & 4 & 23.5 & \multirow{6}{*}{0.510} \\
\hline & Etanercept & 6 & 75.0 & 2 & 25.0 & \\
\hline & Infliximab & 4 & 100.0 & 0 & 0 & \\
\hline & & & & & & \\
\hline & Golimumab & 3 & 50.0 & 3 & 50.0 & \\
\hline & Certolizumab & 6 & 75.0 & 2 & 25.0 & \\
\hline \multirow{4}{*}{ Comorbidity } & $\mathrm{HT}$ & 4 & 44.4 & 5 & 55.6 & 0.020 \\
\hline & DM & 1 & 33.3 & 2 & 66.7 & 0.091 \\
\hline & Asthma & 2 & 66.7 & 1 & 33.3 & 0.750 \\
\hline & $C A D$ & 0 & 0 & 2 & 100.0 & 0.014 \\
\hline \multirow{2}{*}{ TST } & Negative & 22 & 75.9 & 7 & 24.1 & \multirow{2}{*}{0.755} \\
\hline & Positive & 6 & 75.0 & 2 & 25.0 & \\
\hline \multirow{6}{*}{ Additional treatment } & Mesalazine & 3 & 100.0 & 0 & 0 & \multirow{6}{*}{0.726} \\
\hline & Leflunomide & 1 & 100.0 & 0 & 0 & \\
\hline & MTX & 2 & 66.7 & 1 & 33.3 & \\
\hline & CS & 1 & 50.0 & 1 & 50.0 & \\
\hline & Sulfasalazine & 0 & 0 & 1 & 100.0 & \\
\hline & Hydroxychloroquine & 15 & 68.2 & 7 & 31.8 & \\
\hline \multicolumn{2}{|l|}{ Age (years) } & 41 & 12 & 52 & 11 & 0.010 \\
\hline \multicolumn{2}{|c|}{$\operatorname{CRP}(\mathrm{mg} / \mathrm{dl})$} & 1.49 & 3.15 & 1.48 & 1.51 & 0.407 \\
\hline \multicolumn{2}{|c|}{ Number of leukocytes $\left(\times 10^{3} / \mathrm{mL}\right)$} & 7765 & 1645 & 7968 & 2023 & 0.495 \\
\hline \multicolumn{2}{|c|}{ Number of neutrophils $\left(\times 10^{3} / \mathrm{mL}\right)$} & 4594 & 1370 & 5072 & 1523 & 0.329 \\
\hline \multicolumn{2}{|c|}{ Number of lymphocytes $\left(\times 10^{3} / \mathrm{mL}\right)$} & 2478 & 729 & 2203 & 856 & 0.459 \\
\hline \multicolumn{2}{|c|}{$\mathrm{N} / \mathrm{L}$ ratio } & 2.02 & 0.81 & 2.85 & 2.09 & 0.249 \\
\hline \multicolumn{2}{|c|}{ Number of eosinophils $\left(\times 10^{3} / \mathrm{mL}\right)$} & 181 & 113 & 138 & 136 & 0.131 \\
\hline \multicolumn{2}{|l|}{ E/L ratio } & 0.074 & 0.057 & 0.198 & 0.382 & 0.766 \\
\hline \multicolumn{2}{|l|}{ Eosinophil (\%) } & 2.30 & 1.45 & 1.35 & 1.79 & 0.016 \\
\hline \multicolumn{2}{|c|}{ Anti-TNF-alpha treatmentduration (months) } & 54 & 20 & 81 & 44 & 0.082 \\
\hline
\end{tabular}

SD: standard deviation; RA: rheumatoid arthritis; AS: ankylosing spondylitis; HT: hypertension; DM: diabetes mellitus; CAD: coronary artery disease; TST: tuberculin skin test; MTX: methotrexate; CS: corticosteroid; CRP: C-reactive protein, TNF: tumor necrosis factor. Bold values indicate significance at $p<0.05$. 
Table 3. Comparison of demographic, clinical, and laboratory features in COVID-19 (+) patients with and without hospitalization.

\begin{tabular}{|c|c|c|c|c|c|c|}
\hline & \multicolumn{4}{|c|}{ Hospitalization } & \multirow{3}{*}{$p$-value } \\
\hline & & \multicolumn{2}{|c|}{ No } & \multicolumn{2}{|c|}{ Yes } & \\
\hline & & $\mathrm{n}$ or mean & $\%$ or SD & $\mathrm{n}$ or mean & $\%$ or SD & \\
\hline \multirow{2}{*}{ Sex } & Male & 19 & 82.6 & 4 & 17.4 & \multirow{2}{*}{0.778} \\
\hline & Female & 18 & 85.7 & 3 & 14.3 & \\
\hline \multirow{5}{*}{ Rheumatoid disease } & Crohn's disease & 6 & 85.7 & 1 & 14.3 & \multirow{5}{*}{0.623} \\
\hline & RA & 13 & 92.9 & 1 & 7.1 & \\
\hline & AS & 15 & 75.0 & 5 & 25.0 & \\
\hline & Ulcerative colitis & 1 & 100.0 & 0 & 0.0 & \\
\hline & Psoriatic arthritis & 2 & 100.0 & 0 & 0.0 & \\
\hline \multirow{5}{*}{ Anti-TNF-alpha treatment } & Adalimumab & 16 & 88.9 & 2 & 11.1 & \multirow{5}{*}{0.170} \\
\hline & Etanercept & 7 & 87.5 & 1 & 12.5 & \\
\hline & Infliximab & 4 & 100.0 & 0 & 0.0 & \\
\hline & Golimumab & 3 & 50.0 & 3 & 50.0 & \\
\hline & Certolizumab & 7 & 87.5 & 1 & 12.5 & \\
\hline \multirow{4}{*}{ Comorbidity } & HT & 6 & 66.7 & 3 & 33.3 & 0.109 \\
\hline & DM & 1 & 33.3 & 2 & 66.7 & 0.013 \\
\hline & Asthma & 2 & 66.7 & 1 & 33.3 & 0.393 \\
\hline & CAD & 37 & 84.1 & 7 & 15.9 & 0.001 \\
\hline \multirow{2}{*}{ TST } & Negative & 7 & 87.5 & 1 & 12.5 & \multirow{2}{*}{$\begin{array}{l}0.841 \\
0.317\end{array}$} \\
\hline & Positive & 3 & 100.0 & 0 & 0.0 & \\
\hline \multirow{5}{*}{ Additional treatment } & Mesalazine & 1 & 100 & 0 & 0 & \multirow{5}{*}{0.317} \\
\hline & Leflunomide & 1 & 100 & 0 & 0 & \\
\hline & MTX & 4 & 80 & 1 & 20 & \\
\hline & CS & 0 & 0 & 1 & 100 & \\
\hline & Sulfasalazine & 19 & 82.6 & 4 & 17.4 & \\
\hline \multicolumn{2}{|l|}{ Age (years) } & 42 & 12 & 52 & 14 & 0.072 \\
\hline \multicolumn{2}{|l|}{ CRP (mg/dl) } & 1.5 & 2.96 & 1.36 & 1.42 & 0.466 \\
\hline \multicolumn{2}{|c|}{ Number of leukocytes $\left(\times 10^{3} / \mathrm{mL}\right)$} & 7858 & 1696 & 7841 & 2005 & 0.895 \\
\hline \multicolumn{2}{|c|}{ Number of neutrophils $\left(\times 10^{3} / \mathrm{mL}\right)$} & 4642 & 1408 & 5117 & 1343 & 0.426 \\
\hline \multicolumn{2}{|c|}{ Number of lymphocytes $\left(\times 10^{3} / \mathrm{mL}\right)$} & 2508 & 716 & 2060 & 1019 & 0.287 \\
\hline \multicolumn{2}{|l|}{$\mathrm{N} / \mathrm{L}$ ratio } & 2.01 & 0.81 & 3.31 & 2.49 & 0.114 \\
\hline \multicolumn{2}{|c|}{ Number of eosinophils $\left(\times 10^{3} / \mathrm{mL}\right)$} & 176 & 107 & 145 & 167 & 0.145 \\
\hline \multicolumn{2}{|l|}{ E/L ratio } & 0.07 & 0.054 & 0.275 & 0.46 & 0.644 \\
\hline \multicolumn{2}{|l|}{ Eosinophil (\%) } & 2.19 & 1.37 & 1.29 & 2.22 & 0.020 \\
\hline \multicolumn{2}{|c|}{ Anti-TNF-alpha treatmentduration (months) } & 59 & 31 & 67 & 25 & 0.312 \\
\hline
\end{tabular}

SD: standard deviation; RA: rheumatoid arthritis; AS: ankylosing spondylitis; HT: hypertension; DM: diabetes mellitus; CAD: coronary artery disease; TST: tuberculin skin test; MTX: methotrexate; CS: corticosteroid; CRP: C-reactive protein; TNF: tumor necrosis factor. Bold values indicate significance at $p<0.05$. 


\section{DISCUSSION}

The frequency of COVID-19 in cases treated with anti-TNF-alpha treatment was $13.6 \%$. This was more than the frequency in the general population in our country reported by the Turkish Ministry of Health, which was $3.31 \%$. It was revealed previously that COVID19 was more frequent in RA patients compared to the general population ${ }^{3}$. According to the result of previous studies that anti-TNF-alpha treatment might increase the risk for infections ${ }^{8}$, it was speculated that anti-TNF-alpha treatment might also increase the risk for SARS$\mathrm{CoV}-2$ infection and result in poor prognosis. In contrast, later, it has been reported that patients being treated with anti-TNF-alpha agents had a lower risk of hospitalization related to COVID-19 and a better prognosis compared with those treated with other anti-rheumatoid agents, especially $\mathrm{CS}^{1-5}$. This observation was explained with the hypothesis that the TNF-alpha is a cytokine related to the "cytokine storm" and the poor prognosis and mortality, so the blockade of this cytokine might favor the better prognosis in COVID-19.

The TST result did not differ between COVID-19 (-) and (+) groups and patients with and without a history of pneumonia or hospitalization. We evaluated the TST result to indicate immunity against tuberculosis. It was speculated that the Bacillus CalmetteGuérin (BCG) vaccine might have a cross-protective immunity on COVID-19 due to the observation that the prevalence and mortality related to COVID-19 were lower among the countries with routine BCG vaccination?. Several studies were conducted to investigate the relationship between COVID-19 infection and $\mathrm{BCG}$ vaccination ${ }^{10-12}$. Weng et al. reported that patients who were vaccinated with BCG required less hospital admission for COVID$19^{11}$. But, Aksu et al. ${ }^{12}$ reported that older age and low income were the risk factors for developing severe COVID-19 pneumonia while BCG vaccination was not associated with disease severity. The result of our study was compatible with this study, and the patients who suffered from COVID-19 pneumonia were older.

Notably, $25 \%$ of patients suffered from pneumonia, $15.9 \%$ were hospitalized, $2.3 \%$ were followed up in ICU, and $6.8 \%$ needed oxygen treatment. In a multicenter study, the hospitalization rate for COVID-19 among rheumatic patients was reported as $85.5 \%$, while the need for oxygen treatment was $30 \%$, the need for the ICU follow-up was $13 \%$, and the mortality rate was $10 \%{ }^{13}$. In our study, there was no mortality, none of the patients was intubated, and the rate of hospitalization, the need for oxygen treatment, and the ICU follow-up were also lower.

HT and CAD were more frequent among patients with pneumonia, and DM was more frequent among inpatients compatible with the literature, while asthma and COPD were not related to pneumonia and hospitalization. Several studies reported the relationship with the negative effect of comorbidities except for asthma on the course of COVID-19 $9^{14,15}$. The small sample size and presence of few cases with COPD probably caused us to fail to show the relationship between COPD and the prognosis of COVID-19. Wang et al. ${ }^{16}$ and Serling-Boyd ${ }^{17}$ reported that patients with RD had similar risks of poor COVID-19 outcomes with the control group. HT and lung diseases were significantly associated with the increased risk of COVID-19-related hospitalization while the use of anti-TNF-alpha drugs lowered the hospitalization risk in RA patients with COVID-19 ${ }^{16}$.

In this study, the percentage of eosinophils in routine control visits was significantly lower in patients with a history of pneumonia and hospitalization. It was reported that eosinophils have important pro-inflammatory and inflammatory functions in the antiviral response. They can recognize respiratory viruses, respond via releasing cytokines, and lead T-cell activation ${ }^{18-21}$. Several studies demonstrated that leukocytosis, increased number of neutrophils and neutrophil/lymphocyte ratio, and decreased number of lymphocytes and eosinophils at time of admission and follow-up of patients with COVID-19 were related to severe disease and poor prognosis. The mechanisms for eosinopenia in COVID-19 are probably multifactorial, including the decreased synthesis and inhibited migration of eosinophil from the bone marrow and direct eosinophil apoptosis ${ }^{22-24}$. It was suggested that eosinophils might have a protective role during SARS-CoV-2 infection. These observations depend on the blood counts of the patients following SARS-Cov-2 infection, but there was no study about the "basal" blood counts of patients before the infection, so the results of this study may be important in case supported with the results of future studies with more number of cases.

There were few limitations of the study. First, as the sample size of the COVID-19 (+) group was small, we could not determine the odds ratio for the risk factors related to clinical course and outcome of the disease because a specific group of patients was selected, so the results of this study have to be supported with multicentral clinical studies with more cases included. Second, the data about smoking status and BMI were lacking in most of the patients, so we could not discuss these factors in detail.

\section{CONCLUSIONS}

We concluded that the COVID-19 patients treated with antiTNF-alpha agents might have a mild clinical course and a better prognosis. Older age and comorbidities such as $\mathrm{HT}$ and CAD may be related to developing pneumonia. The underlying $\mathrm{RD}$, the anti-TNF-alpha agent used, and the duration of the treatment might not have an effect on the outcome of COVID-19.

\section{AUTHORS' CONTRIBUTIONS}

SB: Conceptualization, Data Curation, Formal Analysis, Writing - Original Draft. OP: Data Curation, Formal Analysis. 


\section{REFERENCES}

1. Arleo T, Tong D, Shabto J, O'Keefe G, Khosroshahi A. Clinical course and outcomes of COVID-19 in rheumatic disease patients: a case cohort study with a diverse population. Clin Rheumatol. 2021;40(7):2633-42. https://doi.org/10.1007/ s10067-021-05578-x

2. Gianfrancesco M, Hyrich KL, Al-Adely S, Carmona L, Danila MI, Gossec L, et al. Characteristics associated with hospitalisation for COVID-19 in people with rheumatic disease: data from the COVID-19 Global Rheumatology Alliance physician-reported registry. Ann Rheum Dis. 2020;79(7):859-66. https://doi. org/10.1136/annrheumdis-2020-217871

3. Robinson PC, Liew DFL, Liew JW, Monaco C, Richards D, Shivakumar $S$, et al. The potential for repurposing anti-TNF as a therapy for the treatment of COVID-19. Med (NY). 2020;1(1):90-102. https://doi.org/10.1016/j.medj.2020.11.005

4. D'Silva KM, Wallace ZS. COVID-19 and disease-modifying anti-rheumatic drugs. Curr Rheumatol Rep. 2021;23(5):28. https://doi.org/10.1007/s11926-021-00998-9

5. Brito CA, Paiva JG, Pimentel FN, Guimarães RS, Moreira MR. COVID-19 in patients with rheumatological diseases treated with anti-TNF. Ann Rheum Dis. 2021;80(5):e62. https://doi. org/10.1136/annrheumdis-2020-218171

6. Bernheim A, Mei $X$, Huang $M$, Yang $Y$, Fayad ZA, Zhang $\mathrm{N}$, et al. Chest CT findings in Coronavirus Disease-19 (COVID-19): relationship to duration of infection. Radiology. 2020;295(3):200463. https://doi.org/10.1148/ radiol.2020200463

7. Guan X, Yao L, Tan Y, Shen Z, Zheng H, Zhou H, et al. Quantitative and semi-quantitative $\mathrm{CT}$ assessments of lung lesion burden in COVID-19 pneumonia. Sci Rep. 2021;11(1):5148. https://doi.org/10.1038/s41598-021-84561-7

8. Au K, Reed G, Curtis JR, Kremer JM, Greenberg JD, Strand V, et al. High disease activity is associated with an increased risk of infection in patients with rheumatoid arthritis. Ann Rheum Dis. 2011;70(5):785-91. https://doi.org/10.1136/ard.2010.128637

9. Escobar LE, Molina-Cruz A, Barillas-Mury C. BCG vaccine protection from severe coronavirus disease 2019 (COVID-19). Proc Natl Acad Sci USA. 2020;117(30):17720-6. https://doi. org/10.1073/pnas.2008410117

10. US National Library of Medicine. Reducing health care workers absenteeism in COVID-19 pandemic through BCG vaccine (BCG-CORONA). ClinicalTrials.gov; 2020. [cited on Apr. 15, 2020]. Available from: https://clinicaltrials.gov/ct2/show/ NCT04328441

11. Weng CH, Saal A, Butt WW, Bica N, Fisher JQ, Tao J, et al. Bacillus Calmette-Guérin vaccination and clinical characteristics and outcomes of COVID-19 in Rhode Island, United States: a cohort study. Epidemiol Infect. 2020;148:e140. https://doi. org/10.1017/S0950268820001569

12. Aksu K, Naziroğlu T, Özkan P. Factors determining COVID-19 pneumonia severity in a country with routine BCG vaccination. Clin Exp Immunol. 2020;202(2):220-5. https://doi.org/10.1111/ cei.13507
13. Esatoglu SN, Tascilar K, Babaoğlu H, Bes C, Yurttas B, Akar $S$, et al. Turkish Society for Rheumatology COVID-19 registry investigators. COVID-19 among patients with inflammatory Rheumatic diseases. Front Immunol. 2021;12:651715. https:// doi.org/10.3389/fimmu.2021.651715

14. Zhang JJ, Dong $X, C$ ao $Y Y$, Yuan $Y D$, Yang $Y B$, Yan $Y Q$, et al. Clinical characteristics of 140 patients infected with SARS-CoV-2 in Wuhan, China. Allergy. 2020;75(7):1730-41. https://doi. org/10.1111/all.14238

15. Li X, Xu S, Yu M, Wang K, Tao Y, Zhou Y, et al. Risk factors for severity and mortality in adult COVID-19 inpatients in Wuhan. J Allergy Clin Immunol. 2020;146(1):110-8. https:// doi.org/10.1016/j.jaci.2020.04.006

16. Wang Q, Liu J, Shao R, Han X, Su C, Lu W. Risk and clinical outcomes of COVID-19 in patients with rheumatic diseases compared with the general population: a systematic review and meta-analysis. Rheumatol Int. 2021;41(5):851-61. https:// doi.org/10.1007/s00296-021-04803-9

17. Serling-Boyd N, D'Silva KM, Hsu TY, Wallwork R, Fu X, Gravalleseet EM, et al. Coronavirus disease 2019 outcomes among patients with rheumatic diseases 6 months into the pandemic. Ann Rheum Dis. 2021;80(5):660-6. https://doi. org/10.1136/annrheumdis-2020-219279

18. Flores-Torres AS, Salinas-Carmona MC, Salinas E, RosasTaraco AG. Eosinophils and Respiratory Viruses. Viral Immunol. 2019;32(5):198-207. https://doi.org/10.1089/ vim. 2018.0150

19. Wong CK, Cheung PF, Ip WK, Lam CW. Intracellular signaling mechanisms regulating toll-like receptor-mediated activation of eosinophils. Am J Respir Cell Mol Biol. 2007;37(1):85-96. https://doi.org/10.1165/rcmb.2006-04570C

20. Drake MG, Bivins-Smith ER, Proskocil BJ, Nie Z, Scott GD, Lee JJ. Human and mouse eosinophils have antiviral activity against parainfluenza virus. Am J Respir Cell Mol Biol. 2016;55(3):38794. https://doi.org/10.1165/rcmb.2015-04050C

21. Su YC, Townsend D, Herrero L, Zaid A, Rolph MS, Gahan ME. Dual proinflammatory and antiviral properties of pulmonary eosinophils in respiratory syncytial virus vaccine-enhanced disease. J Virol. 2015;89(3):1564-78. https://doi.org/10.1128/ JVI.01536-14

22. Huang G, Kovalic AJ, Graber CJ. Prognostic value of Leukocytosis and Lymphopenia for Coronavirus disease severity. Emerg Infect Dis. 2020;26(8):1839-41. https://doi.org/10.3201/ eid2608.201160

23. Lindsley AW, Schwartz JT, Rothenberg ME. Eosinophil responses during COVID-19 infections and coronavirus vaccination. J Allergy Clin Immunol. 2020;146(1):1-7. https:// doi.org/10.1016/j.jaci.2020.04.021

24. Cazzaniga M, Fumagalli LAM, D'angelo L, Cerino M, Bonfanti $\mathrm{G}$, Fumagalli RM, et al. Eosinopenia is a reliable marker of severe disease and unfavourable outcome in patients with COVID-19 pneumonia. Int J Clin Pract. 2021;75(7):e14047. https://doi.org/10.1111/ijcp.14047 